\title{
Genetic variance and genotype reaction norms in response to larval food manipulation for a trait important in scorpionfly sperm competition
}

\author{
L. Engqvist*
}

Department of Evolutionary Biology and Ecology, University of Bonn, Bonn, Germany

\begin{abstract}
Summary
1. Sperm competition is an important attribute of many mating systems. Examining the genetic and environmental factors influencing male sperm competition success is essential in order to understand variation in reproductive success.

2. In the scorpionfly Panorpa cognata, male success in sperm competition is influenced by the number of sperm transferred during copulation. This will be determined by copulation duration and the sperm transfer rate of males. Sperm transfer rate is a trait which shows considerable phenotypic variance.

3. Here, I use a full-sib split-brood design in order to investigate both to what extent this trait is heritable and the influence of larval food availability on male sperm transfer rate.

4. The results demonstrate considerable genetic variance underlying the phenotypic expression of sperm transfer rate. Heritability estimates were slightly larger, but not significantly so, for offspring reared at low food availability.

5. In contrast, there was no straightforward evidence that larval food availability had an effect on the sperm transfer rate of males. However, a significant family $\times$ treatment interaction provided evidence of a genotype $\times$ environment effect on male sperm competitive ability. These results demonstrate different reaction norms for sperm transfer rate in response to larval treatment for individuals with different genetic background.
\end{abstract}

Key-words: ejaculate size, genotype $\times$ environment interactions, Mecoptera, phenotypic plasticity, sperm competition

\section{Introduction}

Sperm competition, the competition between sperm from two or more males for the fertilization of a given set of ova, has been recognized as an important evolutionary force causing strong selection on many male reproductive traits (see, for example, Parker 1970; Eberhard 1996; Simmons 2001; Arnqvist \& Rowe 2005). In many polyandrous mating systems, male reproductive success will, to a large extent, be determined by males' success in the subsequent competition between sperm for fertilizations (Birkhead \& Møller 1998).

Sperm competition success may be affected by many factors such as sperm size (e.g. LaMunyon \& Ward 1998), sperm motility (Birkhead et al. 1999; Gage et al. 2004), longevity (Gage, Stockley \& Parker 1995), or viability (García-González \& Simmons 2005). Nevertheless, sperm number has been widely recognized as the most important trait affecting the

*Correspondence author. E-mail: lengqvist@evolution.uni-bonn.de outcome of sperm competition (e.g. Parker 1982; Dickinson 1986; Parker, Simmons \& Kirk 1990; Eady 1995; Sakaluk \& Eggert 1996; Sauer et al. 1998; Gage \& Morrow 2003). It has also been increasingly acknowledged that individual males may differ considerably in sperm competitive ability (Lewis \& Austad 1990; Dziuk 1996; Radwan 1996; Gage \& Morrow 2003), possibly by differences in sperm number (e.g. Gage \& Morrow 2003). Variance in male competitiveness may be caused by genetic variance in traits affecting sperm competitive ability (e.g. Radwan 1998; Hosken \& Ward 2001; Froman et al. 2002; Simmons \& Kotiaho 2002; Moore et al. 2004). Although variation in traits conferring a strong reproductive advantage may be expected to be depleted through strong directional selection (Fisher 1930; Gustafsson 1986; Mousseau \& Roff 1987), this is generally not the case. In contrast, it has been shown that traits closely associated with fitness, such as sexually selected and important life-history traits, show a particularly high amount of genetic variance (Houle 1992; Pomiankowski \& Møller 1995). The mechanism by which this genetic variation is maintained remains largely unresolved 
(but see Rowe \& Houle 1996; Merilä \& Sheldon 1999). Variance in male sperm competitive ability could also be caused by environmental constraints during development. It has been shown that stressful conditions either during growth or at the time of reproduction may limit optimal development of traits associated with sperm competition (Gage \& Cook 1994; Wedell 1996; Farmer \& Barnard 2000; Engqvist \& Sauer 2001; Hellriegel \& Blanckenhorn 2002). Furthermore, genotypes may differ in their response to different environments, that is, they may show different reaction norms (Roff 1997; Lynch \& Walsh 1998). Such heritable phenotypic plasticity has been documented for sexually selected male traits associated with female mate choice (e.g. Qvarnström 1999; David et al. 2000; Jia, Greenfield \& Collins 2000). Genotype $\times$ environment interactions have also been found when comparing the sperm competition success of different male genotypes within the reproductive environment of different female genotypes (e.g. Wilson et al. 1997; Clark \& Begun 1998; Howard 1999). Yet, the developmental environment of males has rarely been incorporated in genetic studies of male sperm competitiveness. Here I manipulate larval food conditions and study both genetic, environmental and genotype $\times$ environment effects on sperm transfer rate, a trait closely associated with sperm competition success, in the scorpionfly Panorpa cognata Ramb. (Insecta: Mecoptera).

In $P$. cognata, females often mate with several males prior to egg deposition (Engqvist \& Sauer 2003b). Thus, sperm competition will, to a large extent, determine males' reproductive success. In this species, female sperm utilization largely conforms to a fair raffle of sperm (Engqvist et al. 2007, see also Sauer et al. 1998). Therefore, male sperm competition success will be mediated by the relative number of sperm present in female's sperm storage organ at the time of fertilization. As in many scorpionflies, females receive nuptial gifts during courtship, a salivary secretion on which females feed on during copulation (Thornhill 1981; Sauer et al. 1998; Engqvist \& Sauer 2003b; Kock et al. 2006). The size of this salivary mass significantly influences copulation duration (Engqvist \& Sauer 2001), and sperm transfer is continuous during copulation (Sauer, Sindern \& Kall 1997; Engqvist \& Sauer 2003a). Hence, male sperm transfer during copulation and, thus, fertilization success, will be determined by at least two factors (Engqvist et al. 2007): (i) copulation duration, which will be influenced by a male's ability to secrete a large amount of saliva prior to copulation; and (ii) the rate of sperm transfer (i.e. the amount of sperm transferred per unit time). Both traits show large phenotypic variance (Engqvist \& Sauer 2001, 2003a). Saliva production is highly dependent on male food availability during the adult phase. Consequently, males in better body condition are able to secrete larger salivary masses (Engqvist \& Sauer 2001; see also Engels \& Sauer 2006). Yet, not much is known about the factors causing male variance in sperm transfer rate (see Engqvist \& Sauer 2003a; Engqvist et al. 2007). In contrast to salivary secretion, this trait does not seem to be influenced considerably by adult condition (Engqvist \& Sauer 2003a). Nevertheless, there are vast differences between males in their capability of fast sperm transfer, ranging from approximately one to eight sperm per minute. These differences in sperm transfer rate will directly affect male fertilization success because, overall, fast sperm pumpers will have more of their sperm stored in the females' spermatheca (Engqvist et al. 2007). Thus, understanding variance in sperm transfer and the factors causing it is important in order to fully understand the properties of sexual selection in this mating system. Differences in sperm transfer ability may originate from larval development, rather than from adult conditions (e.g. Gage \& Cook 1994). In scorpionflies, males inject sperm into the females' spermatheca by means of a sperm pump, a large muscular organ placed in the centre of the males' characteristic scorpion-like genital segment (Grell 1942). Nutritional constraints during larval development may possibly hamper the optimal development of this powerful organ or any other trait necessary for effective sperm transfer. In this study, I therefore investigated the impact of larval nutrition on male sperm transfer rate. By using a full-sib split-brood design, my aim was also to estimate the amount of genetic variation for this trait and to examine if different genotypes show different reaction norms in response to larval food conditions.

\section{Materials and methods}

In this study, the sperm transfer rate of males in a parent generation (fathers) was first estimated. Full-sib offspring of these males were subsequently reared on two different larval food diets. After adult emergence, the sperm transfer rate of males in this offspring generation (sons) was determined.

\section{BREEDING OF PARENT GENERATION}

The parental generation were all $F_{1}$ offspring from animals caught near Freiburg i. Br. in south-western Germany. Larval food consisted of small cut mealworms (Tenebrio molitor). Larvae were reared on a $12 \mathrm{~L}: 12 \mathrm{D}$ photoperiod and, as third larval instars, transferred to outdoor cylinders: soil-filled, open-bottomed plastic cylinders $(\varnothing 40 \mathrm{~cm}$, depth $1 \mathrm{~m}$ ) placed outdoors in the ground, where they overwintered. Adults were collected at the day of emergence (May 2003). For details of breeding protocols, see Sauer $(1970,1977)$ and Thornhill \& Sauer (1992)

\section{BREEDING OF OFFSPRING GENERATION}

A full-sib split-brood design was used. Before the breeding of offspring, the sperm transfer rates of sires were estimated in standardized mating trials (see below) beginning at the age of 14 days. For the breeding of offspring, unrelated females and males were randomly paired and put into transparent mating boxes $(10 \times 10 \times 7 \mathrm{~cm})$ containing moist filter paper. Pairs were observed to ensure that females and males actually copulated. Mating trials that failed were repeated until they were successful or the would-be sire was discarded from the experiment. Females were subsequently kept individually in plastic oviposition boxes containing moist filter paper, a peat-filled Petri dish for oviposition and food ad lib. Boxes were inspected daily for egg laying. Eggs were carefully transferred from the Petri dish for egg laying to a new Petri dish containing moist tissue paper. 
Following larval hatching, broods were split and the larvae were randomly assigned to the two treatments: Larvae were either reared on a diet that consisted of 10 or $30 \mathrm{mg}$ freeze-dried mosquito larvae (Astra ${ }^{\circledR}$ Aquaria, Bissendorf, Germany) every 8th day. Larvae were kept individually in small plastic Petri dishes $(\varnothing 5.2 \mathrm{~cm})$ containing moist filter paper and food at $18^{\circ} \mathrm{C}$ on a 18 L:6 D photoperiod enabling diapause-free development (see Sauer 1970). Every eighth day, Petri dishes were changed to avoid fungi invasion. On the 26th day, fourth instar larvae were transferred to peat-filled cylinders $(\varnothing 3.5 \mathrm{~cm}$, peat depth $c .5 \mathrm{~cm})$, where they entered the pupal stage and finally emerged. No food was provided during this phase. At emergence, offspring male hatch weight was determined to the nearest $0 \cdot 1 \mathrm{mg}$. Following emergence, all males were held on a diet consisting of a one-segment piece of mealworm every third day (see, for example, Engqvist \& Sauer 2001, 2003a). As for sires, mating trials were performed in order to estimate the sperm transfer rate of sons, beginning at the age of 14 days. As a measure of body size, the mean length of the left and right forewings was used. Measurements were made to the nearest $0 \cdot 1 \mathrm{~mm}$ with a dissecting microscope at $10 \times$ magnification.

\section{MEASURING SPERM TRANSFER RATE}

For both fathers and sons, sperm transfer ability was measured in standardized mating trials (Engqvist \& Sauer 2003a; Engqvist 2006). Trials were staged with one female and one male in transparent plastic boxes $(10 \times 10 \times 7 \mathrm{~cm})$ containing moist filter paper and a piece of stem and leaf from a nettle plant (Urtica dioica). In both parent and offspring generation, females were randomly chosen from a stock that were bred under similar conditions as described above for the $F_{1}$ generation. Since female weight has an influence on male sperm transfer rate in P. cognata (Engqvist \& Sauer 2003a), only females with body weights ranging from 47.5 to $52.5 \mathrm{mg}$ were chosen for the mating trials. Within this small range, variance in sperm transfer rate due to female weight differences have been shown to be negligible (see also Engqvist et al. 2007). In order to estimate the rate of male sperm transfer, copulations were interrupted after exactly $120 \mathrm{~min}$ by gently touching the pairs (see also Engqvist \& Sauer 2003a). If mating trials failed - either the pair did not mate at all or they did not copulate for $120 \mathrm{~min}$ - they were repeated each day until the male successfully mated with the female and sperm number could be measured. Mated females were killed under $\mathrm{CO}_{2}$ anaesthesia and dissected on the next day. Dissections and sperm counts were performed using standard protocols (cf. Sauer et al. 1997; Engqvist \& Sauer 2003a).

Sperm transfer rate is practically stable during copulation (Engqvist et al. 2007). Measuring sperm transfer over $120 \mathrm{~min}$ has proven practicable, as in the laboratory most matings exceed this duration. Still it lies well within the range of naturally occurring uninterrupted copulations (Engqvist \& Sauer 2003b; Engqvist 2007). The estimation of male sperm transfer rate using this standardized protocol has been shown to be highly repeatable (Engqvist \& Sauer 2003a; Engqvist et al. 2007). Furthermore, this estimate of male sperm transfer rate is closely connected with male fertilization success in sperm competition (Engqvist et al. 2007).

\section{STATISTICAL ANALYSIS}

The slopes from the regressions of sperm transfer rate of fathers on the mean sperm transfer rate of sons were used to estimate narrow sense heritability of sperm transfer rate. As sons were reared under two different conditions, I first performed two separate regressions. Heritabilities can be estimated from father-son regressions as $h^{2}=2 \times b$, where $b$ denotes the slope of the linear regression (Falconer \& Mackay 1996; Roff 1997).

In the data set, the number of sons per family (family size) in each treatment varied between 1 and $5($ mean $=2 \cdot 2)$. Following Lynch \& Walsh (1998, pp. 539-542), I therefore used weighted least-square regressions to minimize sampling error of the heritability estimates. Each observation was weighted by the inverse of the residual sampling variances of family means about the father-son regression. The weight of the $i$ th family can be calculated as

$w_{i}=n_{i} /\left(n_{i}\left(t-b^{2}\right)+(1-t)\right)$,

where $n_{\mathrm{i}}$ is the size of family $i, t$ is the intraclass correlation between sibs (Sokal \& Rohlf 1995, pp. 213-214) and $b^{2}$ is the square of the regression slope for the father-son regression. Since $b^{2}$ is a function of the regression coefficient and, hence, of the heritability itself, I used an iterative re-weighting procedure to estimate the weights. The iteration syntax (which can be obtained from me upon request) was written in R $2 \cdot 4 \cdot 1$ (Ihaka \& Gentleman 1996) using the function $l m$ with the argument weights to specify family weights in the weighted regression model.

The effect of larval food treatment was analysed using a mixed model ANOVA. In these analyses, family was entered as a random factor and food treatment was entered as a fixed factor. Thus, this analysis gives both an estimate of the effect of larval food availability as well as an estimate of genetic $\times$ environment interactions on male sperm transfer rate. By analysing variances between families for both treatments separately, it is also possible to obtain estimates of heritabilities from a full-sib design using formulas described in Falconer \& Mackay (1996) and Roff (1997). The mixed model ANOva was performed with SPSS 12.0 (SPSS Inc., Chicago, Illinois, USA).

\section{Results}

In total, I measured the sperm transfer rate of 110 sons descending from 25 sires. For 24 of these sires, I successfully obtained an estimate of sperm transfer rate (mean \pm SD sperm transfer rate: $501 \cdot 0 \pm 110 \cdot 3$ ). Fifty-four of the offspring males were bred at low food availability whereas 56 were bred at high food availability.

Father-son regressions revealed considerable variance in offspring phenotype attributable to the phenotype of sires (Fig. 1), especially for offspring bred under low food availability (low food: $h^{2}=0 \cdot 704 \pm 0 \cdot 35$, Fig. 1a; high food: $h^{2}=0.526 \pm 0 \cdot 49$, Fig. 1b). However, the slope was only marginally significant for the regression on offspring bred under low food availability $\left(t_{22}=2.01 ; P=0.056\right)$ and not for the high food availability treatment $\left(t_{20}=1.05 ; P=0.3\right)$. Nonetheless, slopes, and thus the heritability, did not differ between offspring treatments (ANCOVA: sperm transfer rate of father $\times$ offspring treatment $\left.F_{1,41}=1 \cdot 42 ; P=0 \cdot 24\right)$. An analysis of the whole data set revealed a significant influence of sires on the sperm transfer rate of sons $\left(h^{2}=0 \cdot 655 \pm 0 \cdot 27\right.$, $t_{22}=2 \cdot 45, P=0 \cdot 023$, Fig. 1c).

Male offspring assigned to the high food treatment were both significantly heavier and larger than offspring in the low food treatment (mean $\pm \mathrm{SE}$ hatch weight: low food, $19.43 \pm 0.38 \mathrm{mg} ;$ high food, $22.54 \pm 0.37 \mathrm{mg} ; F_{1,108}=34 \cdot 7$, 

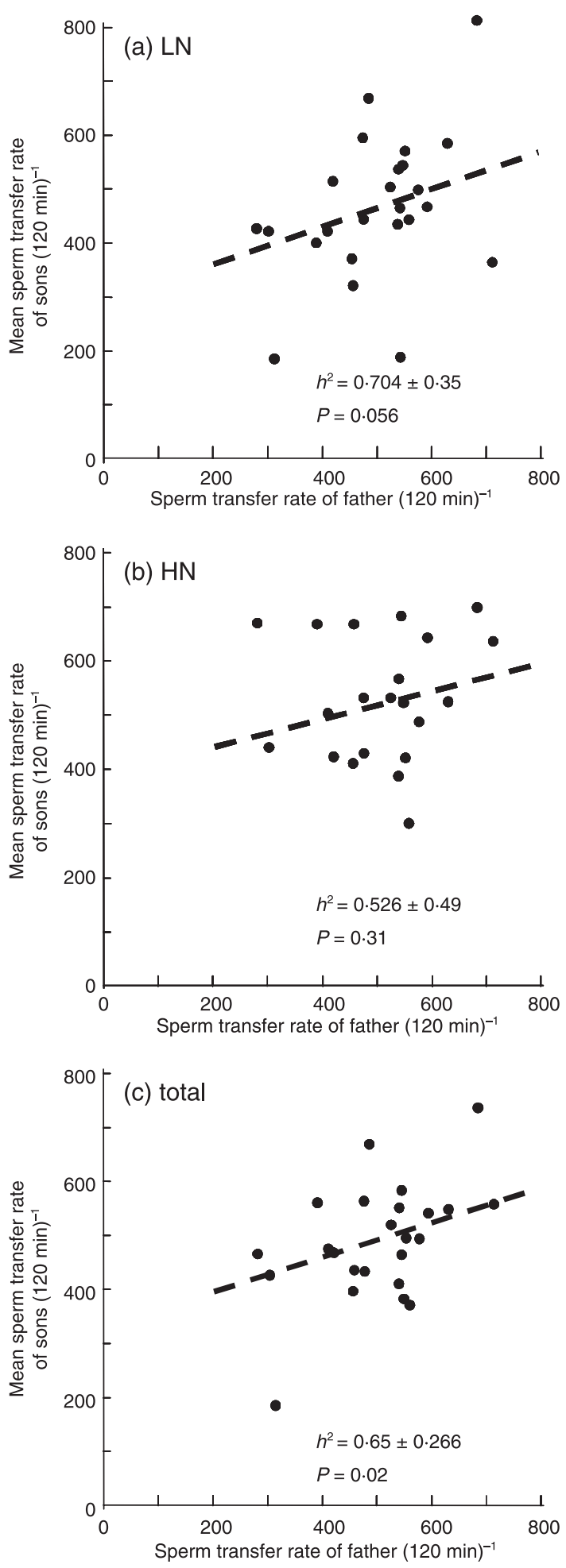

Fig. 1. Father-son regressions of sperm transfer rate for (a) sons reared at low larval food availability, (b) sons reared at high food availability and (c) for the pooled data set. The lines indicate the weighted least-square regressions.

$P<0.001$; size: low food, $11 \cdot 36 \pm 0.055 \mathrm{~mm}$; high food, $\left.11 \cdot 81 \pm 0.054 \mathrm{~mm} ; F_{1,107}=32.5, P<0.001\right)$. Moreover, there were significant overall positive correlations both between offspring hatch weight and sperm transfer rate $(r=0 \cdot 251$,

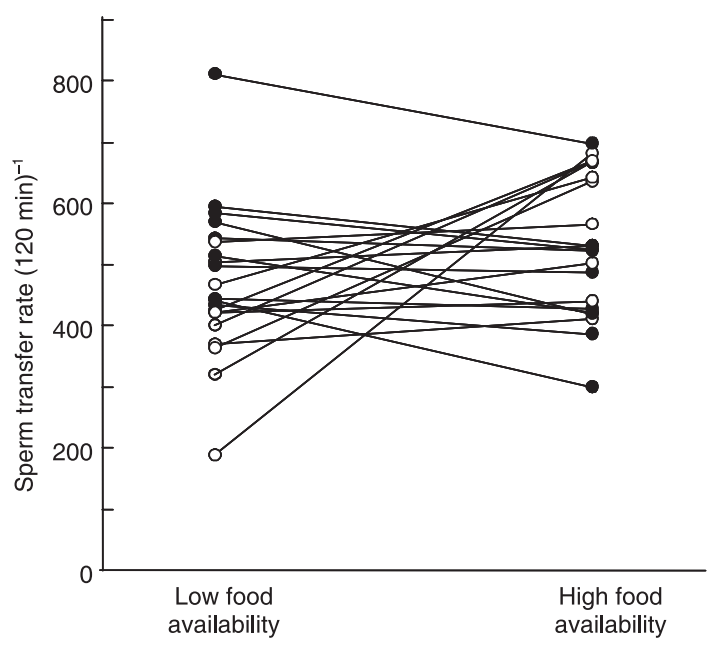

Fig. 2. Reaction norms for sperm transfer rate in response to larval food availability for different genotypes. Each point represents the mean value for full-sibs in each treatment, respectively. Lines connect the mean values of full-sib groups. Full-sibs which responded with an average increase in sperm transfer rate with increasing larval food availability are depicted with open circles; those with a decrease are depicted with closed circles.

$n=110, P=0.008)$ as well as between offspring size and sperm transfer rate $(r=0 \cdot 270, n=109, P=0 \cdot 005)$. Consequently, there was an overall effect of larval food availability on sperm transfer rate, which was significantly higher for males reared under high food conditions (offspring low food: $453 \cdot 2 \pm 20 \cdot 3$ sperm $\times(120 \mathrm{~min})^{-1}$; high food: $526 \cdot 4 \pm 19 \cdot 9$ sperm $\left.\times(120 \mathrm{~min})^{-1} ; F_{1,108}=6 \cdot 62, P=0 \cdot 011\right)$. However, after including family effects into the model, this difference was no longer statistically significant (mixed model ANOVA: treatment $\left.F_{1,23 \cdot 1}=1 \cdot 44 ; P=0 \cdot 24\right)$. Nevertheless, there was a significant genetic $\times$ environment interaction affecting offspring sperm transfer rate (mixed model ANOvA: family $\times$ treatment $F_{19,65}=2 \cdot 05 ; P=0 \cdot 016$ ). Thus, larval food treatment evidently affects males differently depending on genetic descent (Fig. 2). An analysis of between-family variance for both treatments separately revealed significant genetic variance, at least for offspring reared at low food availability (low food availability: ANOVA, family: $F_{23,30}=2 \cdot 26 ; P=0 \cdot 018$; high food availability: ANOvA, family: $\left.F_{21,34}=1.83 ; P=0.056\right)$. The estimated mean \pm SE full-sib heritability equalled $0.725 \pm 0.32$ in the low food availability treatment and $0.497 \pm 0.32$ for offspring bred under high food availability.

\section{Discussion}

This study aimed at investigating the effect of larval food availability on sperm transfer rate and estimating the amount of genetic variance for this trait. It revealed considerable genetic variance in male sperm transfer rate in this species (Fig. 1), whereas the effect of larval food treatment was more ambiguous (Fig. 2), yet revealed by a significant genotype $\times$ environment interaction.

Quantitative genetic studies on traits pictured to be important in sperm competition are still comparatively scarce in 
comparison to other fitness-associated traits (see e.g. Bakker \& Pomiankowski 1995; Pomiankowski \& Møller 1995; Roff 1997; Bakker 1999). This study adds to a growing body of studies showing that traits important in sperm competition may show considerable heritable variation (see, for example, Sakaluk 1988; Radwan 1998; LaMunyon \& Ward 1999; Morrow \& Gage 2001; Pitnick et al. 2001; Simmons \& Kotiaho 2002; Moore et al. 2004). Yet, to my knowledge, no study has incorporated genetic differences in plasticity in response to the developmental environment. The maintenance of substantial genetic variance for sperm transfer is intriguing, as selection is expected to eliminate variability in traits closely associated with male reproductive success (Fisher 1930; Gustafsson 1986; Mousseau \& Roff 1987). High genetic variance in sperm competition traits can be explained if there is a genetic correlation between these traits and condition (Simmons \& Kotiaho 2002) because condition is likely to be affected by a very large number of loci (Rowe \& Houle 1996; Merilä \& Sheldon 1999) and may therefore be exposed to higher mutational variability (Houle, Morikawa \& Lynch 1996). This genic capture explanation would also require that experimental manipulation of condition would affect the expression of these condition-dependent traits (Andersson 1986; Iwasa, Pomiankowski \& Nee 1991; Rowe \& Houle 1996; see also Tomkins et al. 2004). However, a previous study manipulating adult condition (Engqvist \& Sauer 2003a) did not provide any unequivocal evidence of condition dependence of male sperm transfer rate.

Nevertheless, condition dependence might primarily be operating during larval development. Larval food stress may cause significant reduction in traits associated with sperm competition, such as sperm number or testis weight (e.g. Gage \& Cook 1994; Hellriegel \& Blanckenhorn 2002). In the present study, larval food consumption during development had no lucid effect on male sperm transfer rate. Overall, larger and heavier males that received more food during larval development appear to be superior sperm pumpers. However, the effect of larval food availability is nonhomogeneous as genotypes show different reaction norms revealed by a significant genotype $\times$ treatment interaction. The capture of genetic variance by condition-dependent traits (Rowe \& Houle 1996) may be expected to cause such an effect (e.g. David et al. 2000) but would require that the order of genotypes is maintained across environments (Tomkins et al. 2004). Inspection of the different reaction norms (Fig. 2) reveals a different, albeit ambiguous, pattern. Most families showed only a weak response to larval food availability, for which the genetic correlation over environments seems rather stable (indicated by more or less horizontal parallel lines). Yet, a few families showed a very strong response: intriguingly, these five genotypes were among the very best in high food availability but scored well under average in low food availability (Fig. 2). These genotypes alone would suggest mutations to have positive effect in one environment but negative, deleterious effects in the other, causing genotype reaction norms to cross (see Greenfield \& Rodriguez 2004; Tomkins et al. 2004). Such genotype $\times$ environment interactions might maintain genetic variation because a single genotype cannot be most fit in all environments (Gillespie \& Turelli 1989).

Evolution of optimal sperm transfer rate may also be constrained by trade-offs among different traits affecting male sperm competition (e.g. Moore et al. 2004) or by trade-offs between traits affecting sperm transfer and traits affecting mating success (Warner et al. 1995; Danielsson 2001). Sperm transfer is associated with muscle contractions of the sperm pump (Grell 1942), and it has been suggested that sperm transfer may be energetically costly (Engqvist \& Sauer 2003a). Energetically costly behaviour is often associated with high resting metabolic rate (Reinhold 1999), which will increase basal energy expenditure, possibly reducing energy resources to be spent on, for instance, salivary gland development or somatic maintenance. Thus, the eventual cost of sperm transfer may only be established by including the study of other fitness traits.

In conclusion, this study on sperm transfer rate in the scorpionfly $P$. cognata demonstrates high genetic variability for a trait closely associated with male sperm competition success. When comparing all offspring, larval food conditions influenced male sperm transfer rate, and heavier and larger males appear superior sperm pumpers. However, this effect is solely based upon strong plasticity in a few genotypes only, whereas most genotypes showed no or only a weak response. Thus, the genotypic reaction norms in response to larval food stress have revealed some interesting patterns. Yet, further studies are needed to fully understand the genetic and phenotypic constraints affecting male sperm transfer ability in $P$. cognata.

\section{Acknowledgments}

Joachim Frommen and two anonymous reviewers gave constructive comments on a previous version of the manuscript. Julia Leven, Alexander Weiß, Kim Schmidt and Nicole Schmidt helped me in the laboratory. This study was supported by a grant from the Deutsche Forschungsgemeinschaft [En 469-1/1].

\section{References}

Andersson, M. (1986) Evolution of condition-dependent sex ornaments and mating preferences: sexual selection based on viability differences. Evolution, 40, 804-816.

Arnqvist, G. \& Rowe, L. (2005) Sexual Conflict. Princeton University Press, Princeton.

Bakker, T.C.M. (1999) The study of intersexual selection using quantitative genetics. Behaviour, 136, 1237-1266.

Bakker, T.C.M. \& Pomiankowski, A. (1995) The genetic basis of female mate preferences. Journal of Evolutionary Biology, 8, 129-171.

Birkhead, T.R. \& Møller, A.P., eds (1998) Sperm Competition and Sexual Selection. Academic Press, San Diego.

Birkhead, T.R., Martinez, J.G., Burke, T. \& Froman, D.P. (1999) Sperm mobility determines the outcome of sperm competition in the domestic fowl. Proceedings of the Royal Society of London, Series B, 266, 1759-1764.

Clark, A.G. \& Begun, D.J. (1998) Female genotypes affect sperm displacement in Drosophila. Genetics, 149, 1487-1493.

Danielsson, I. (2001) Antagonistic pre and post-copulatory sexual selection on male body size in a water strider (Gerris lacustris). Proceedings of the Royal Society of London, Series B, 268, 77-81.

David, P., Bjorksten, T., Fowler, K. \& Pomiankowski, A. (2000) Conditiondependent signalling of genetic variation in stalk-eyes flies. Nature, 406, $186-188$.

Dickinson, J.L. (1986) Prolonged mating in the milkweed beetle Labidomera clivicollis clivicollis (Cleoptera: Chrysomelidae): a test of the 'sperm loading' hypothesis. Behavioral Ecology and Sociobiology, 18, 331-338. 
Dziuk, P.J. (1996) Factors that influence the proportion of offspring sired by a male following heterospermic insemination. Animal Reproduction Science, 43, 65-88.

Eady, P.E. (1995) Why do male Callosobruchus maculatus beetles inseminate so many sperm? Behavioral Ecology and Sociobiology, 36, 25-32.

Eberhard, W.G. (1996) Female Control: Sexual Selection by Cryptic Female Choice. Princeton University Press, Princeton.

Engels, S. \& Sauer, K.P. (2006) Resource dependent nuptial feeding in Panorpa vulgaris: an honest signal of male quality. Behavioral Ecology, 17, 628632.

Engqvist, L. (2006) Females benefit from mating with different males in the scorpionfly Panorpa cognata. Behavioral Ecology, 17, 435-440.

Engqvist, L. (2007) Nuptial gift consumption influences female remating in a scorpionfly: male or female control of mating rate? Evolutionary Ecology, 21, 49-61.

Engqvist, L. \& Sauer, K.P. (2001) Strategic male mating effort and cryptic male choice in a scorpionfly. Proceedings of the Royal Society of London, Series B, 268, 729-735.

Engqvist, L. \& Sauer, K.P. (2003a) Determinants of sperm transfer in the scorpionfly Panorpa cognata: male variation, female condition and copulation duration. Journal of Evolutionary Biology, 16, 1196-1204.

Engqvist, L. \& Sauer, K.P. (2003b) Influence of nutrition on courtship and mating in the scorpionfly Panorpa cognata. Ethology, 109, 911-928.

Engqvist, L., Dekomien, G., Lippmann, T., Epplen, J.T. \& Sauer, K.P. (2007) Sperm transfer and paternity in the scorpionfly Panorpa cognata: large variance in traits favoured by postcopulatory episodes of sexual selection. Evolutionary Ecology doi: 10.1007/s10682-006-915-6.

Falconer, D.S. \& Mackay, T.F.C. (1996) Introduction to Quantitative Genetics, 4th edn. Longman, Harlow.

Farmer, D.C. \& Barnard, C.J. (2000) Fluctuating asymmetry and sperm transfer in male decorated field crickets (Gryllodes sigillatus). Behavioral Ecology and Sociobiology, 47, 287-292.

Fisher, R.A. (1930) The Genetical Theory of Natural Selection. Clarendon Press, Oxford.

Froman, D.P., Pizzari, T., Feltmann, A.J., Castillo-Juarez, H. \& Birkhead, T.R. (2002) Sperm mobility: mechanisms of fertilizing efficiency, genetic variation and phenotypic relationship with male status in the domestic fowl, Gallus gallus domesticus. Proceedings of the Royal Society of London, Series $B, 269,607-612$.

Gage, M.J.G. \& Cook, P.A. (1994) Sperm size or number? Effects of nutritional stress upon eupyrene sperm production strategies in the moth Plodia interpunctella (Lepidoptera: Pyralidae). Functional Ecology, 8, 594-599.

Gage, M.J.G., Macfarlane, C.P., Yeates, S., Ward, R.G., Searle, J.B. \& Parker, G.A. (2004) Spermatozoal traits and sperm competition in Atlantic salmon: relative sperm velocity is the primary determinant of fertilization success. Current Biology, 14, 4447.

Gage, M.J.G. \& Morrow, E.H. (2003) Experimental evidence for the evolution of numerous, tiny sperm via sperm competition. Current Biology, 13, 754 757.

Gage, M.J.G., Stockley, P. \& Parker, G.A. (1995) Effects of alternative male mating strategies on characteristics of sperm production in the Atlantic salmon (Salmo salar): theoretical and empirical investigations. Philosophical Transactions of the Royal Society of London Series B - Biological Sciences, 350, 391-399.

García-González, F. \& Simmons, L.W. (2005) Sperm viability matters in insect sperm competition. Current Biology, 15, 271-275.

Gillespie, J.H. \& Turelli, M. (1989) Genotype-environment interactions and the maintenance of polygenic variation. Genetics, 121, 129-138

Greenfield, M.D. \& Rodriguez, R.L. (2004) Genotype-environment interaction and the reliability of mating signals. Animal Behaviour, 68, 14611468 .

Grell, K.G. (1942) Der Genitaltraktus von Panorpa communis L. Ein weiterer Beitrag zur Anatomie und Histologie der Mecopteren. Zoologische Jahrbücher: Abteilung für Anatomie und Ontologie der Tiere, 67, 513-588.

Gustafsson, L. (1986) Lifetime reproductive success and heritability: empirical support for Fisher's fundamental theorem. American Naturalist, 128, 761764

Hellriegel, B. \& Blanckenhorn, W.U. (2002) Environmental influences on the gametic investment of yellow dung fly males. Evolutionary Ecology, 16, 505522.

Hosken, D.J. \& Ward, P.I. (2001) Experimental evidence for testis size evolution via sperm competition. Ecology Letters, 4, 10-13.

Houle, D. (1992) Comparing evolvability and variability of quantitative traits. Genetics, 130, 195-204.

Houle, D., Morikawa, B. \& Lynch, M. (1996) Comparing mutational variabilities. Genetics, 143, 1467-1483.
Howard, D.J. (1999) Conspecific sperm and pollen precedence and speciation. Annual Review of Ecology and Systematics, 30, 109-132.

Ihaka, R. \& Gentleman, R. (1996) R: a language for data analysis and graphics. Journal of Computational and Graphical Statistics, 5, 299-314.

Iwasa, Y., Pomiankowski, A. \& Nee, S. (1991) The evolution of costly mate preferences. II. The 'handicap' principle. Evolution, 45, 1431-1442.

Jia, F.Y., Greenfield, M.D. \& Collins, R.D. (2000) Genetic variance of sexually selected traits in waxmoths: maintenance by genotype $\times$ environment interaction. Evolution, 54, 953-967.

Kock, D., Hardt, C., Epplen, J.T. \& Sauer, K.P. (2006) Patterns of sperm use in the scorpionfly Panorpa germanica, L. (Mecoptera: Panorpidae). Behavioral Ecology and Sociobiology, 60, 528-535.

LaMunyon, C.W. \& Ward, S. (1998) Larger sperm outcompete smaller sperm in the nematode Caenorhabditis elegans. Proceedings of the Royal Society of London, Series B, 265, 1997-2002.

LaMunyon, C.W. \& Ward, S. (1999) Evolution of sperm size in nematodes: sperm competition favours larger sperm. Proceedings of the Royal Society of London, Series B, 266, 263-267.

Lewis, S.M. \& Austad, S.N. (1990) Sources of intraspecific variation in sperm precedence in red flour beetles. American Naturalist, 135, 351-359.

Lynch, M. \& Walsh, B. (1998) Genetics and Analysis of Quantitative Traits. Sinnauer, Sunderland.

Merilä, J. \& Sheldon, B.C. (1999) Genetic architecture of fitness and nonfitness traits: empirical patterns and development of ideas. Heredity, 83, 103-109.

Moore, P.J., Harris, W.E., Montrose, V.T., Levin, D. \& Moore, A.J. (2004) Constraints on evolution and postcopulatory sexual selection: trade-offs among ejaculate characteristics. Evolution, 58, 1773-1780.

Morrow, E.H. \& Gage, M.J.G. (2001) Artificial selection and heritability of sperm length in Gryllus bimaculatus. Heredity, 87, 356-362.

Mousseau, T.A. \& Roff, D.A. (1987) Natural selection and the heritability of fitness components. Heredity, 59, 181-197.

Parker, G.A. (1970) Sperm competition and its evolutionary consequences in the insects. Biological Reviews, 45, 525-567.

Parker, G.A. (1982) Why are there so many tiny sperm? Sperm competition and the maintenance of two sexes. Journal of Theoretical Biology, 96, 281-294.

Parker, G.A., Simmons, L.W. \& Kirk, H. (1990) Analysing sperm competition data: simple models for predicting mechanisms. Behavioral Ecology and Sociobiology, 27, 55-65.

Pitnick, S., Miller, G.T., Reagan, J. \& Holland, B. (2001) Males' evolutionary responses to experimental removal of sexual selection. Proceedings of the Royal Society of London, Series B, 268, 1071-1080.

Pomiankowski, A. \& Møller, A.P. (1995) A resolution of the lek paradox. Proceedings of the Royal Society of London, Series B, 260, 21-29.

Qvarnström, A. (1999) Genotype $\times$ environment interactions in the determination of the size of a secondary sexual character in the collared flycatcher (Ficedula albicollis). Evolution, 53, 1564-1572.

Radwan, J. (1996) Intraspecific variation in sperm competition success in the bulb mite: a role for sperm size. Proceedings of the Royal Society of London, Series B, 263, 855-859.

Radwan, J. (1998) Heritability of sperm competition success in the bulb mite, Rhizoglyphus robini. Journal of Evolutionary Biology, 11, 321-327.

Reinhold, K. (1999) Energetically costly behaviour and the evolution of resting metabolic rate in insects. Functional Ecology, 13, 217-224.

Roff, D.A. (1997) Evolutionary Quantitative Genetics. Chapman \& Hall, New York.

Rowe, L. \& Houle, D. (1996) The lek paradox and the capture of genetic variance by condition dependent traits. Proceedings of the Royal Society of London, Series B, 263, 1415-1421.

Sakaluk, S.K. (1988) Inheritance of male parental investment in an insect. American Naturalist, 132, 594-601.

Sakaluk, S.K. \& Eggert, A.-K. (1996) Female control of sperm transfer and intraspecific variation in sperm. Evolution, 50, 694-703.

Sauer, K.P. (1970) Zur Monotopbindung einheimischer Arten der Gattung Panorpa (Mecoptera) nach Untersuchungen im Freiland und im Laboratorium. Zoologische Jahrbücher: Abteilung für Systematik, Ökologie und Geographie der Tiere, 97, 201-284.

Sauer, K.P. (1977) The adaptive significance of genetic variability of photoperiodic response in Panorpa vulgaris. Zoologische Jahrbücher: Abteilung für Systematik, Ökologie and Geographie der Tiere, 104, 489-538.

Sauer, K.P., Sindern, J. \& Kall, N. (1997) Nutritional status of males and sperm transfer in the scorpionfly Panorpa vulgaris (Mecoptera: Panorpidae). Entomologica Generalis, 21, 189-204.

Sauer, K.P., Lubjuhn, T., Sindern, J., Kullmann, H., Kurtz, J., Epplen, C. \& Epplen, J.T. (1998) Mating system and sexual selection in the scorpionfly Panorpa vulgaris (Mecoptera: Panorpidae). Naturwissenschaften, 85, 219-228.

Simmons, L.W. (2001) Sperm Competition and its Evolutionary Consequences in the Insects. Princeton University Press, Princeton. 
Simmons, L.W. \& Kotiaho, J.S. (2002) Evolution of ejaculates: patterns of phenotypic and genotypic variation and condition dependence in sperm competition traits. Evolution, 56, 1622-1631.

Sokal, R.R. \& Rohlf, F.J. (1995) Biometry, 3rd edn. W. H. Freeman, New York.

Thornhill, R. (1981) Panorpa (Mecoptera: Panorpidae) scorpionflies: systems for understanding resource-defense polygyny and alternative male reproductive efforts. Annual Review of Ecology and Systematics, 12, 355-386.

Thornhill, R. \& Sauer, K.P. (1992) Genetic sire effects on the fighting ability of sons and daughters and mating success of sons in a scorpionfly. Animal Behaviour, 43, 255-264.

Tomkins, J.L., Radwan, J., Kotiaho, J.S. \& Tregenza, T. (2004) Genic capture and resolving the lek paradox. Trends in Ecology \& Evolution, 19, 323-328.
Warner, R.R., Shapiro, D.Y., Marcanato, A. \& Petersen, C.W. (1995) Sexua conflict - males with highest mating success convey the lowest fertilization benefits to females. Proceedings of the Royal Society of London, Series B, 262, 135-139.

Wedell, N. (1996) Mate quality affects reproductive effort in a paternally investing species. American Naturalist, 148, 1075-1088.

Wilson, N., Tubman, S.C., Eady, P.E. \& Robertson, G.W. (1997) Female genotype affects male success in sperm competition. Proceedings of the Royal Society of London, Series B, 264, 1491-1495.

Received 8 March 2007; accepted 1 August 2007

Handling Editor: Charles Fox 